\title{
A Study of Befriending and Its Use on Suicide Prevention in India
}

\author{
Amitabh Roy*
}

\section{ABSTRACT:}

The Goal of this study was to understand the concept of Befriending and its effects on Suicide Prevention in India. In view of the above purpose we studied the model of Befriending across the world and in India. The data was collected from 3 NGOs based out of Ahmedabad, Mumbai and Chennai. According to the data in the year 2006, Suicide rates had increased marginally up-to $1,18,11,12$. It is observed that there is an increase in Suicide rate more among men than women.

Keywords: Suicide in India

\section{INTRODUCTION}

Befriending is a fairly new concept in India. It can be done by both an individual and an organization. The aim of this study was to understand Befriending and its methodology and its use and effectiveness on Suicide Prevention in India.

\section{What is Befriending?}

"A treatment for Depression or Emotional distress that is "non- Judgmental", mutual \& purposeful".

Another definition of "Befriending" is as social support that was "initiated, supported and monitored by an agency" expressly one or more parties to benefit.

\section{Use of Befriending for Suicide Prevention:}

A group of volunteers called the Samaritans, begun in England in 1953 by Reverend Chad Varah. The service extended by the Samaritans is simply that of "befriending". The Befriended offers support to the suicidal person with no strings attached. He/she is available to listen and to help in whatever way he/she can, expecting nothing - not even gratitude - in return. Since there founding, the Samartians have spread throughout the British Commonwealth and in many other parts of the world

*The Author is a Masters in Psychology from EIILM UNIVERSITY,8th Mile, Budang, Malabassey, West Sikkim- 737121, India.

(C) 2014 A Roy; licensee IJIP. This is an Open Access Research distributed under the terms of the Creative Commons Attribution License (http://creativecommons.org/licenses/by/2.0), which permits unrestricted use, distribution, and reproduction in any Medium, provided the original work is properly cited. 


\section{OBJECTIVES}

1. To understand the concept of Befriending

2. To understand the methodology used in Befriending

3. To find out how it has been helpful for Suicide prevention in India

\section{METHODOLOGY}

\section{Befriending by an Individual}

1. To offer Emotional support, understanding, patience and encouragement.

2. Engage your friend in conversation, and listen carefully

3. Never disperse feelings of your friend or relative expresses, but point out realities and offer hope

4. Never Ignore comments about suicide, and report them to your friend's relatives, therapist or doctor.

5. Invite your friend or relative out for walks, outings and other activities. Keep trying if he/she declines, but don't push him/her to take on too much too soon. Although diversions and company are needed, too many demands may increase feelings of failure.

6. Remind your friend or relative that with time and treatment, the depression will lift.

In case of an NGO/Centre offering befriending the following methodology/charter is followed:

1. Total Confidentiality is offered

2. Provide Emotional support to people when they are Suicidal

3. The volunteers who serve at the Centre also seek to alleviate misery, loneliness, despair and depression by listening to those who feel they cannot turn to anyone else who would understand and accept them.

4. Contact with the agency does not limit individual freedom, which is further protected by the right to remain anonymous.

5. The fact that someone has been in contact with the Centre whether by telephone, letter, Email, visit or any other means) is confidential, so too is everything revealed by or about the person.

6. The Centre's are nonpolitical and nonsectarian and the volunteers do not seek to impose their own convictions on anyone.

7. The Centre may on certain occasion request the advice of professional consultants.

8. In appropriate circumstances individuals may be invited to consider seeking professional help in addition to the support offered by a Centre.

\section{Things a Centre does not do:}

1. No Advise is given to the person - even if the volunteer thinks that he/she has an answer to the person's problems. 
2. The Centre does not promise the person that they will undertake any action on their behalf without first discussing it with the person in charge of the agency.

3. The Volunteers do not judge the person or criticize their behavior

4. The Centre does not trace person's details like phone numbers, names, address etc.

5. The Centre does not send for an ambulance without the person's consent (unless, under certain circumstances, the person becomes unconscious).

6. The Centre volunteers do not meet the person or make contact with them outside normal center operating procedures.

\section{NETWORK OF SUICIDE PREVENTION CENTRE USING BEFRIENDING IN INDIA}

A member of the Befrienders India network, which comes under the aegis of Befrienders Worldwide having over 400 center's around the world, Befrienders India started11 Helplines spread across 4 cities, they are as follows:

1. SAATH an NGO based out of Ahmedabad

2. JEEVAN an NGO based out of Jamshedpur

3. MAITHRI KOCHI an NGO based out of Kerala

4. PRATHEEKSHA an NGO based out of Kerala

5. SNEHA an NGO based out of Chennai

6. THANAL CALICUT an NGO based out of Calicut

7. SAMARITANS MUMBAI an NGO based out of Mumbai

8. AASRA an NGO based out of Navi Mumbai

9. SUMAITRI an NGO based out of New Delhi

10. ROSHINI an NGO based out of Secunderabad

11. LIFELINE FOUNDATION an NGO based out of Kolkata

All these NGO are non-profit organization entirely run by volunteers who offer emotional support to the distressed, depressed and suicidal. The volunteers seek to alleviate misery, loneliness and despair by listening, in a non-judgmental way, to those who cannot turn to anyone else who would understand and accept them. The caller remains anonymous and everything said to the volunteer remains confidential

Centres are mainly resourced by volunteers. Volunteers are selected, trained, mentored and supported by other experienced volunteers and any necessary relevant professional experts. Centres are mutually supportive and committed to sharing information with other member Centre's, and participating in processes and activities of the network

The work of the network's Centre's is outstanding and vital. Capturing their abilities and achievements in suicide prevention will allow for a global exchange of knowledge and practice, developing new global processes that will improve the quality of their experience as volunteers, and ultimately the service they deliver. 


\section{STATISTICS}

1. AASRA a NGO based in Navi Mumbai has been working on Suicide Prevention. It started its operations from $13^{\text {th }}$ September 1998. As per them below are the facts and data in regards to Suicide.

- Every 40 seconds a life is lost through suicide (Worldwide as per WHO data). Suicide Rate (India 2006-07): General Population-11.5 \% per lakh. Army-7.5 \% per lakh. Mumbai: (As per Police stats) 3 lives lost per day due to suicide. Navi Mumbai As per Police stats) 2 lives lost per week due to suicide

- In India according to National Crime Records Bureau 110,417 people committed suicide in the year 2002, which is $1.8 \%$ more than compared to 2001., i.e.; a suicide is committed every five minutes. Seven times that number attempt to take their lives and as for those who feel desperate and unable to cope, the number is mind boggling. More suicides occur between 18 and 45 - in other words in the most productive age group of our society.

- Every 3 seconds a person attempts to die.

- Suicide is one of the top three causes of death among the young in the age group of 15-35 years

- The psychological, social and financial impact of suicide on the family and the society is immeasurable.

- About 1 lakh people die by suicide in India every year.

- 3 people in a day in Mumbai commit suicide.

- 2 in a week in Navi Mumbai commit suicide.

- Each suicide leaves at least 6 people devastated.6 lakhs people become survivors every year in India.

- Suicide estimates suggest fatalities worldwide could rise to 1.5 million by 2020 . Suicide is a largely preventable public health problem, causing almost half of all violent deaths as well as economic costs in the billions of dollars, says the WHO.

Dr Catherine Le Gals-Camus, WHO Assistant-Director General, Non-communicable Diseases and Mental Health said: "World-wide, more people die from suicide than from all homicides and wars combined. There is an urgent need for coordinated and intensified global action to prevent this needless toll. For every suicide death there are scores of family and friends whose lives are devastated emotionally, socially and economically."

- Suicide rates tend to increase with age, but there has recently been an alarming increase in suicidal behaviors amongst young people aged 15 to 25 years old, worldwide. With the exception of rural China, more men than women commit suicide, although in most places more women than men attempt suicide.

- Some [pointers regarding stress and depression and suicide culled from The WEEK magazine. 2008 survey) Mid-year special.

- Under High stress your biological age can be 30 times higher than your calendar age. 
- $69 \%$ of people suffering from stress related disorders such as depression were apprehensive that society would consider them to be crazy.55\% of people suffering from stress related disorders say they have no or very few close friends.71\% people under stress refrain from social activities.50\% of people under stress say they are not able to pursue leisure activities or hobbies.

- The typical age of onset of social anxiety disorder is 12 to 19

- $77 \%$ people under stress say anxiety or disorders such as insomnia or depression hamper their romantic relationships.

- $58 \%$ are embarrassed to acknowledge that they are depressed.

- $35 \%$ people suffering from social anxiety disorder say they avoid intimacy with partners.

- A study says $72 \%$ writers, $42 \%$ artists, $41 \%$ politicians, $36 \%$ intellectuals, $35 \%$ musicians and 33\% scientists are prone to stress related disorders.

- Depression among the youth has increased from $2 \%$ to $12 \%$ in the last five years. Globally 3 out of every 5 visits to the doctor are for stress related problems. $76 \%$ people under stress say they have sleeping disorders and 58\% suffer headaches. Laughing helps ease stress. And laughing 100 times equals 10 minutes of working out on a rowing machine or 15 minutes of cycling. 85\% of people under stress tend to have strained relations with family and friends. $70 \%$ of people under stress say they have become short-tempered. A NIMHANS study says $36 \%$ techies in Bangalore show signs of psychiatric disorder. Globally 1 out of every 10 students suffer significant distress. Over $50 \%$ of lost workdays across the world are due to stress, says an ILO study. 16000 students in India committed suicide between 2004 and 2008

- According to reports 50\% employees in India Inc are under stress :30\% have problems such as addictions and marital discord.20\% suffer from depression.

- Depression is the No 1 occupational disease of the 21 st century says WHO. $49 \%$ of people under stress say they suffer from upset stomach or nausea. $71 \%$ people undress stress feel they are not productive and cry regularly.

- Over 50\% of the World's children are brought up in stressful conditions, says UNESCO. 1 in every 20 IT professionals contemplates suicide, says NIMHANS study. The US govt spends $\$ 3$ billion per year on stress related issues such as compensation claims, medical expenses and reduced productivity.

- Children laugh about 300 times a day while adults laugh only 15 to 100 times. India currently has only about 3500 psychiatrists. Analysts say there must be at least a threefold increase in strength to help a growing tribe of people suffering from stress related disorders.

- $66 \%$ CEO's in India are stressed out and $11 \%$ find it too much to handle says ASSOCHAM.72\% of students in India are unaware of how to deal with stress and it's illeffects. In 2006 alone 5,857 students committed suicide owing to exam stress.27.6\% of IT professionals in India are addicted to narcotic drugs says a NIMHANS study. 
2. SNEHA an NGO based in Chennai has been working in the field of suicide intervention for the past 25 years. Since its inception in 1986, over 1,50,000 people have utilized there services.

\section{SUICIDE STATISTICS}

\begin{tabular}{|c|c|c|c|c|c|c|c|c|c|c|}
\hline \multirow{2}{*}{ Year } & \multicolumn{3}{|c|}{ CHENNAI } & \multicolumn{3}{|c|}{ TAMIL NADU } & \multicolumn{3}{|c|}{ INDIA } & \multirow{2}{*}{ Rate } \\
\hline & Male & Female & Total & Male & Female & Total & Male & Female & Total & \\
\hline 1992 & & & & & & & & & 80149 & 9.24 \\
\hline 1993 & & & & & & & & & 84244 & 9.53 \\
\hline 1994 & & & & & & & & & 89195 & 9.91 \\
\hline 1995 & & & & & & & & & 89178 & 9.74 \\
\hline 1996 & & & & & & 9003 & & & 88241 & 9.47 \\
\hline 1997 & & & & & & 9197 & & & 95829 & 10.03 \\
\hline 1998 & & & & & & & & & 104713 & 10.79 \\
\hline 1999 & & & 1142 & 6644 & 4804 & 11448 & & & 110587 & 11.21 \\
\hline 2000 & 685 & 399 & 1084 & 6769 & 4207 & 10976 & 66032 & 42561 & 108593 & 10.84 \\
\hline 2001 & 646 & 444 & 1090 & 7149 & 4190 & 11339 & 66314 & 42192 & 108506 & 10.57 \\
\hline 2002 & 851 & 510 & 1361 & 6983 & 4261 & 11244 & 69332 & 41085 & 110417 & 10.51 \\
\hline 2003 & 749 & 489 & 1238 & 7154 & 4718 & 11872 & 70221 & 40630 & 110851 & 10.4 \\
\hline 2004 & 663 & 533 & 1196 & 7946 & 4893 & 12839 & 72651 & 41046 & 113697 & \\
\hline 2005 & 1333 & 942 & 2275 & 7507 & 4569 & 12076 & 72916 & 40998 & 113914 & \\
\hline 2006 & 1501 & 926 & 2427 & & & 12381 & 75702 & 42410 & 118112 & 11.3 \\
\hline 2007 & 1534 & 779 & 2313 & 8687 & 5124 & 13811 & 79295 & 43342 & 122637 & 10.8 \\
\hline 2008 & 818 & 491 & 1309 & 9043 & 5382 & 14425 & 80544 & 44473 & 125017 & 10.8 \\
\hline 2009 & 909 & 503 & 1412 & 8950 & 5474 & 14424 & 81471 & 45680 & 127151 & 10.9 \\
\hline
\end{tabular}

\section{CONCLUSION}

Befriending is fairly a new concept in India; it is a tool that has been regularly used by Catholic institutions, NGO's, Government agencies across the globe and in India to counsel people. The concept of Suicide Prevention Centre's is not more than a decade old in our country and is spreading across our nation. Currently we have about 11 centers run by Befrienders India network spread across the country. Befriending is an effective tool which has helped people to gain trust in themselves and helped them to come out of depression and lead a normal life. It has been successful in preventing suicide attempts in more than $90 \%$ of cases which have been handled by these centers in India and abroad. But keeping in view of the increasing suicide rates there is a need of more such suicide prevention Centre's in India. The Government needs to set up or collaborate with such institutions and help them reach more people who are in need of their services. Befriending alone cannot help people having depression, but can give them a temporary relief from their current burning situation. A professional help is always helpful in cases where suicidal tendencies are seen. Befriending cannot be termed as a therapy but could be a stop gap 
solution to the problem he/she is facing. It helps the person to realize his/her current situation and helps him/her to take out time and think on the problems he/she is facing and to some extent gives them the strength and courage to face their issues/problems with a more practical approach.

\section{REFERENCES \& SOURCES}

1. AASRA an NGO based in Navi Mumbai, working on Suicide Prevention

2. Abnormal Psychology and Modern Life by James C Coleman; Chapter 17, Suicide, page no 603

\section{BEFRIENDERS WORLDWIDE}

4. Irene $\mathrm{S}$ Levine, $\mathrm{PhD}$ in the Friendship Doctor - "Is Befriending a treatment for depression?" - Published on Feb 7, 2010

5. SAATH an NGO based in Ahmedabad, working on Suicide Prevention

6. SNEHA an NGO based in Chennai, working in the field of suicide intervention 